ISBN 978-81-933894-1-6

International Conference on Arts, Social Sciences, History and Interdisciplinary Studies

(ASSHIS-2017)

Kyoto (Japan) April 20-21, 2017

\title{
E-Governance towards Local Participatory Planning in Developing Country (A Study about the Implementation of "E-Musrenbang” In Surabaya, Indonesia)
}

\author{
Choiriyah Basnawi ${ }^{1}$, and Hikmatus Sabilil ${ }^{2}$ \\ ${ }^{1}$ Department of Social and Political Science, Airlangga University, Indonesia \\ ${ }^{2}$ Department of Social and Political Science, Airlangga University, Indonesia
}

\begin{abstract}
The rise of issues related to accountability and transparency prompted the government to be able to increase their performance and capacity. In order to improve their performance, E-Government or Electronicbased government is implemented by city officials in Surabaya-Indonesia. E-Government is an innovation that facilitate the process of planning, implementation and evaluation of the overall development process that is undertaken by government electronically. Development planning process in Indonesia is closely related to Musrenbang as a planning mechanism that incriminate citizen as the main actors of planning. Therefore, city officials seek to improve the performance of Musrenbang supported by Internet network creating an innovation called "E-musrenbang"

This qualitative study using in-depth interviews, observation, and secondary data that is collected from Bappeko. Researchers also collect, identify, analyze, and organize synthesis of data to interpret the application of the system E-planning forums. This paper explores the case of E-Musrenbang implementation as an innovative form of development planning system which serves to accommodate the entire community over planning proposals online. E-musrenbang conducted under Bappeko as a public city planning and development agency that embodies the community's proposal in planning process. The paper aims to understand more about technology utilize in E-Musrenbang that can affect community participation in planning and development. EMusrenbang is not only changed the mechanism from manual to electronic, but also provide other facilities that give a convenience for the citizen in proposal making process.

The paper pointed out that community is highly participated in E-Musrenbang process. Accordance with the city strategic plan formulation, although it's not directly (face to face interaction) it can be said that the community has been involved on it. Thus, participatory planning can be achieved in planning and realization of the values and goals that are desirable in the city development planning process. This means, with the advancement of information and technology, it can be connecting the city government, stakeholders and the public to be able to draft an appropriate development. It is hoped that this paper can provide a picture of the success implementation of e-musrenbang in the development planning process. It is expected to contribute to the other developing countries to fully implement this similar planning and development patterns in order to realize a more participative development planning in their country.
\end{abstract}

Keywords: E-Governance, E-Musrenbang, Participatory Planning, Development.

\section{E-Governance}

The development of Information and Communication Technology (ICT) in the era of globalization is important because ICT support human to meet their needs in terms of getting information. Nowadays ICT has been used in various fields such as human education, culture, government and others. In the field of education, people can access information about education theme with ease so that humans can develop their knowledge and know many things that support education. In the field of culture, people can access the cultures in order to know the diversity of cultures. While in government, the government can take advantage of the Internet network to 
support the implementation of his governmental process. The government can share information to the public, access information related to the policies, interact with the community and so on.

\subsection{What is E-Governance?}

The rise of issues related to accountability and transparency encourages the goverment to vastly improve their performance capacity. In order to improve the performance, city officials supported by advances in technology implement the "E-Governance" or Electronic-based governance. Heeks (2003) said that egovernance is the ICT-enabled route to achieving good governance. In e-government, the government uses information technology and particularly the Internet to support government operations, engage citizens, and provide government services (Palvia, 2007). E-governance is the application of information and communication technology (ICT) for delivering government services, exchange of information communication transactions, integration of various stand-alone systems and services between government-to-customer (G2C), governmentto-business (G2B), government-to-government (G2G) as well as back office processes and interactions within the entire government framework (Estevez, 2007). Moreover The UNESCO definition of E-governance from unesco.org says that "E-governance is the public sector's use of information and communication technologies with the aim of improving information and service delivery, encouraging citizen participation in the decisionmaking process and making government more accountable, transparent and effective. E-governance involves new styles of leadership, new ways of debating and deciding policy and investment, new ways of accessing education, new ways of listening to citizens and new ways of organizing and delivering information and services. E-governance is generally considered as a wider concept than e-government, since it can bring about a change in the way citizens relate to governments and to each other. E-governance can bring forth new concepts of citizenship, both in terms of citizen needs and responsibilities. Its objective is to engage, enable and empower the citizen."

\subsection{E-Governance in Surabaya, Indonesia}

Surabaya City has implemented the E-Goverment since 2002, even before the regulations regarding to the procurement of goods and services electronically exist. Presidential Decree of the Guidelines for Procurement of Government Goods / Services which includes a new electronic auction system is provide by the governance in 2003. This proves the outstanding initiative of the government of Surabaya to run an excellence process of administration. Quoted from the page the Ministry of the state apparatus empowerment of Indonesia, they apreciate the implementation and development of e-government that is carried out by the Surabaya City Government, they will make it as a benchmark national electronic government system. Surabaya along with three other regions proposed to receive an award from the United Nations because of their E-governance.

E-governance that is implemented by the Surabaya City Government classified into two, First is in terms of financial management, and the second is for community service. Financial managers areas include e-budgeting, e-project, e-procurement, e-delivery, e-controlling, and e-performance. While dealing with the public, it is called E-sapawarga, which include e-licensing, e-musrenbang, and a system that facilitate the people so that they can make a complaints electronically. Here is the example of E-governance implementation in Surabaya, Indonesia :

- For E-sapawarga, Surabaya City Government provides free internet facilities throughout the RT as a Neighborhood Association and RW as a Citizen Association, so that the whole program can be accessed by the public. Submission of making some types of letter of permission given for free, one of them such as a license to do business. People just need to enter data as required. A completed form then verified for processing, if the data is correct then the license will be issued. Government employees will drive directly to the applicant's residence.

- E-health apply their medical record at the clinic. Data throughout the patient can be accessed via the Internet, so that the patients who come to the clinic do not need to bring their medical record data manually. Simply attach the finger, then all the data has appeared on the monitor. 
- The preparation of the budget system, conducted by E-budgeting. In it lists all fees required by the service, ranging from small to a large scale expenditure. Pricing using specific standards, each department must use e-budgeting in the proposed budget. Before they adopt E-governance, the recording is done using a hard copy (book), now with e-budgeting, everything becomes more simple because it is done electronically.

- The next step is to make E-project planning. E-project is to determine when items should be auctioned, whether there were done in self-managed, or when a form of cooperation ends. All controlled every month via e-Controlling.

- E-Controlling to determine the physical progress of each activity every month, whether it is in accordance with the plan or not. With the E-controlling, government aim to minimize counterfeiting price, this is because inputting data is directly done by the provider of goods or services.

- With the Internet network, every beginning year of budgenting the citizen can propose a project, for example such as construction of access roads, training program for citizen, various empowerment program, street lighting, construction of the library, and others via E-musrenbang. This proposal will be screened for later realized in the next year. E-Musrenbang was discussed at the sub-district level, then the result is taken to the district level, and the last is in the city government. Results of E-musrenbang used as material in the Designing Plan Budget of Regions that will be discussed by parliament.

\section{E-Musrenbang and Participation}

Implementation of E-Government give an effect to the overall process of establishing government, but in this paper will focus the discussion on the planning stage that is associated with the development process in Surabaya. Involving citizens in making plans is a cornerstone for good planning practice (Seltzer, 2013). Development planning process involving citizens in Indonesia is closely related to Musrenbang as a planning mechanism that incriminate citizen as the main actors of planning. This is based on Local Government law which explains that the determination of the construction of facilities and infrastructure of local villages and community development is done through local development forum in accordance with the provisions of the legislation. Therefore, city officials seek to improve the performance development planning process with Internet network to create an innovation called e-musrenbang.

E-musrenbang system has been carried out since 2009 by the Surabaya City Government as an integral concept of development planning and participatory to accommodate the proposals of citizens in terms of development. Things behind the innovation of e-musrenbang is the development of information and communication technology in various fields. In addition, the e-planning forums are expected to create a participatory development in order to achieve the vision and mission of Surabaya City. E-musrenbang conducted under Badan Perencanaan Pembangunan Kota Surabaya (Bappeko) as a public city planning and development agency that embodies the community's proposal in planning process

With e-musrenbang, Surabaya City Government can easily capture the aspirations of citizens and carrying out development in accordance with the vision and mission of Surabaya. In addition, e-musrenbang help people to communicate with the government so that people can contribute to development. The idea of the Musrenbang at an earlier time still done manually and files are still sent manually from the public. So in 2009 after the innovation of E-Musrenbang, people can upload the proposal online on Bappeko official website that is musrenbang.surabaya.go.id. Everyone can access and see what proposals are made by people for the government. E-Musrenbang Surabaya changes and develop from year to year. At the first appearance in the 2009 , data entry is done just the mere conversion of an excel file to the website, so the data entry can be made directly to the website by the people. But earlier in the year 2009-2011, data entry is handled at the district level, so the neighborhoods and villages only send files to each district.

In addition in the early appearance of e-musrenbang it still has no standard types of jobs. The absence of standardization causes people to freely leave the title name of the type of work in accordance with what they 
want. It will be difficult for the fasilitatior when they make the data recapitulation of proposal because the title used is different even it's actually same type of proposal. Moreover, because the number of incoming proposals are not few even up to thousands of kinds of proposals, it would be difficult for the facilitator to organised about 7000 incoming proposals. Therefore, in the subsequent development, a data filter proposal is designed to facilitate and simplify the task of facilitator in the process of proposals identification.

With the proposal filter, people only have to choose the type of work and what type of work that they want to propose. People already no need to be confused to give or make the name or title of the type of work they want to ask. As well as the the facilitator, inputed data will be categorized automatically so that it will simplify and shorten the process of grouping data proposal.

In addition to the lack of standardization with these types of jobs other inadequacies of the E-Musrembang at the beginning of their appearance is still no standard of price, so at first people themselves who determine the price that is required as the budget of proposal they put forward. Problems will arise if there is a proposal with a same criteria, but there is no standard budget so that the funds budgeted can be so different because there is no number of a fixed price which became the standard budget of each type of jobs on proposal. Therefore, along with the development of this site they invented innovation of standardization prices for each type of the proposals.

The price or the budget required is already provided and get listed on every desired type of proposal. This minimizes the possibility of overbudgeting or error in pricing due to the lack of public knowledge in determining the price. The government itself is not arbitrary in determining the price. In determining the price the government is using the comparison value, the comparative value here is the value of the average price of one unit from three different places (goods or services providers). Thus the price indicated in the budget ceiling is expected to be the standard price is not too cheap and not too expensive.

E-musrenbang technology until now has evolved where now e-musrenbang using spatial analysis based on Geographic Information System (GIS) through involving the participation.

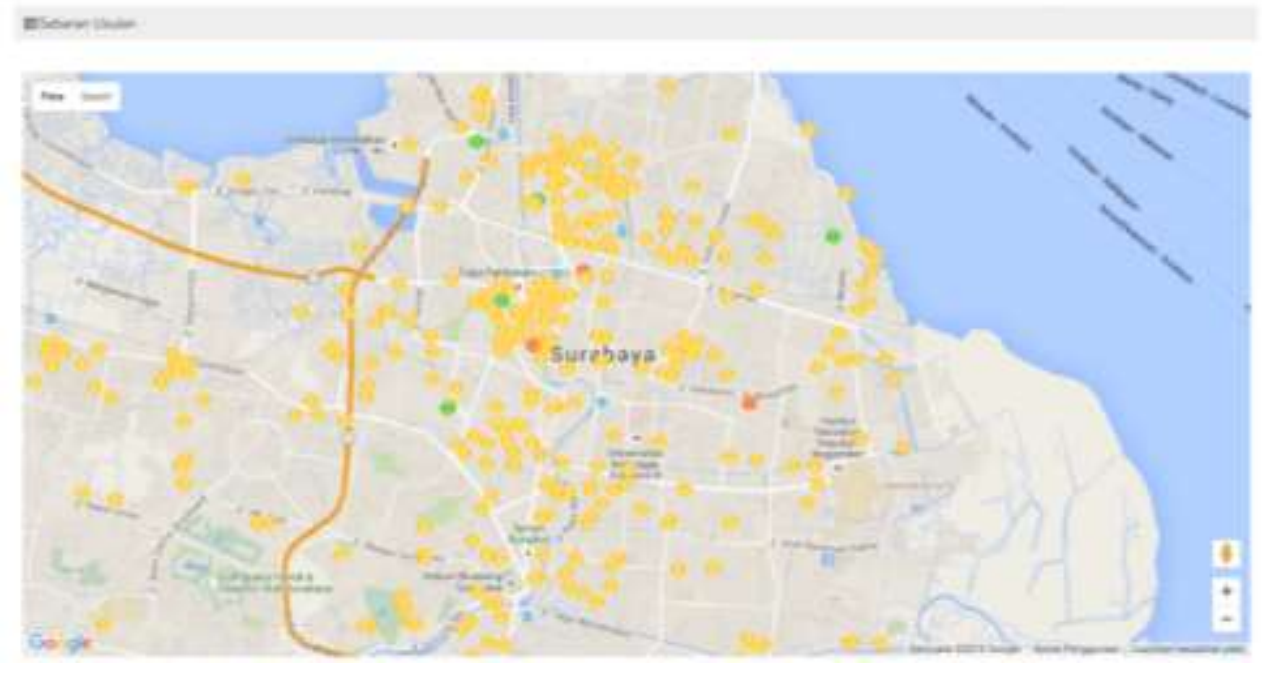

Fig. 1 : Proposal Distribution Map (from bappeko.surabaya.go.id/musrenbang2016)

Although it using spatial analysis based, GIS still refers to the Standards Unit Price. GIS helps in ranking priorities in computerized so as to facilitate the government in managing data accurately and quickly. All data proposals can be grouped according to type of proposal, so it can be seen the spread of a proposal anywhere. So it is expected at the future it can be used to process a more comprehensive analysis. For example if you want to accept the proposal of construction of the school, will first be examined how much the spread of existing schools in the sub-district and then check the number of population density there, next new proposal on the construction of the school decided whether it was accepted or rejected. 
Is not just put the proposals online, but of deliberation or discussion process was still running as usual through the website E-Musrenbang. Topic discussed in the deliberations usually about what to proposed, place or location of deliberation, and others. Musrenbang in district region will hold consultation with the sub-district and the RW as a whole and should be existing official report had been agreed. The results of these deliberations was given to BAPPEKO (City Development Planning Agency) in the form of one sheet of paper to be used as evidence signed in accordance with the Regulation of the deliberations.

\section{E-Musrenbang's Flow}

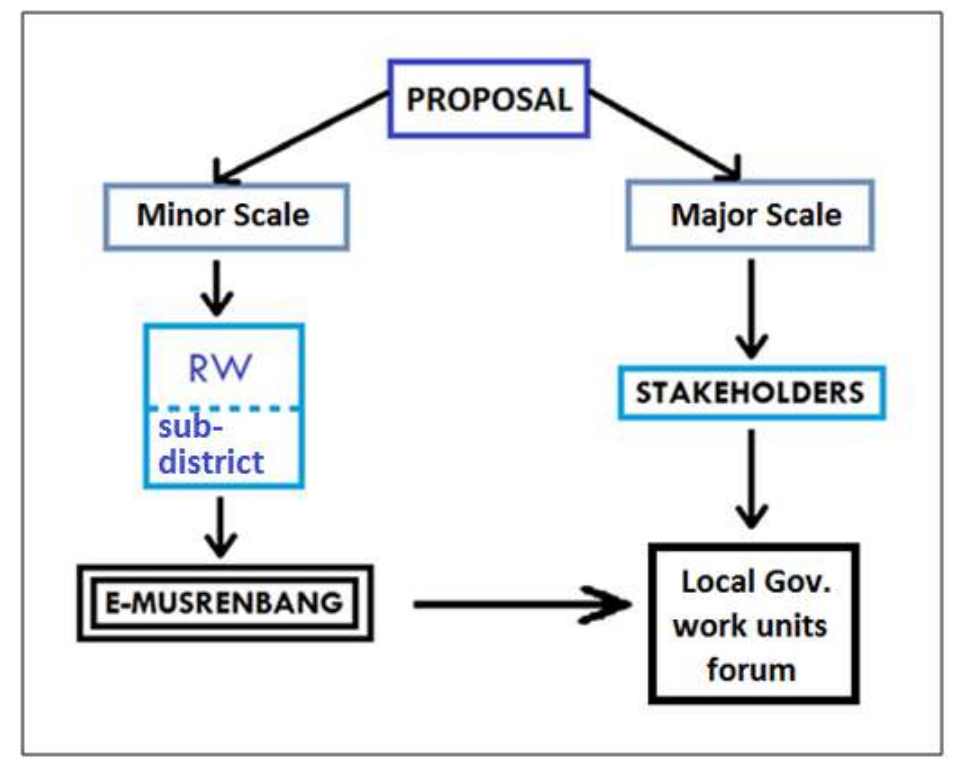

Fig. 2 : E-Musrenbang plot

From the chart above, we can understand the position of e-musrenbang in the development planning process. Development planning in Surabaya is based on proposals from the community and the realization of the vision and mission of the Mayor of Surabaya. The proposals are divided into the minor scale and major scale of proposals. minor-scale proposal was a proposal submitted by the citizens of Surabaya, the proposals accommodated by each RW and sub-district to inputted into the e-musrenbang. Each RW can give a maximum of two proposals, and they will get a passcode or password to input their proposal. Meanwhile major scale of proposal was a proposal submitted by the stakeholders. Both minor and a major scale of proposal will be recorded and then discussed in the forum of the Local Government Unit to conducted the assessment.

Keep in mind that the proposals contained in E-musrenbang only a proposal which is on a low scale, is still not covers proposals that are on a big scale. To better understand the flow of E-Musrenbang, following is the elaboration stages from the E-Musrenbang plot in Surabaya:

- Suggestions given by society through RW of each region in the city of Surabaya entered in the EMusrenbang website. Each representative of RW receive username to access the E-Musrenbang to login and perform to input the proposal.

- In order for detail so that the proposals can be verified, the proposals from each RW is accompanied by: First, an attached photos (optional), The photos were used to determine the real situation of the current condition of the area that is proposed. State have a role to dicede whether the region feasible to be built or not. Second, there will be a survey from the related agencies to check the real situation of the area that is proposed. The parties who handle the project is also diffrent adapted to the needs of development. The survey was also carried out by the related department whether it should be realized or not, how the mechanism, to prove that the proposal deserves to be approved. However, sometimes such development is not evenly distributed so that in the system of E-Musrenbang will be listed mapping of territoriality in order 
to determine which areas are still need to be concerned, so it will minimize inequality but equitable growth in every region in Surabaya .

- Based on the data attached to it, a proposal is stated to be approved or not by Government. The reasons for approval or rejection of proposal is also attached on the website to promote the openness. Accepted proposal will be processed to be inserted into E-budgetting process, and which are not approved will be considered for next year's budgeting process. In addition, proposal restrictions are also regulated by limit, the maximum budget allocated for each sub-district is Rp 1.059 billion, -. If sub-district proposals budget does not reach the limit, then the rest amout of budget can not be used again next year. Because the ceiling is just an ammout that is used as a limitation, not a nominal in the form of money.

- Once the process is completed, the of E-Musrenbang been established where proposal are acceptable where the proposal was rejected. The next will be held a face to face forum named Local Government Work Unit Forum, the forum was attended by stakeholders, relevant agencies, Bappeko, and community representatives, proposals have been approved (RW). Forum Local Government Unit not only discuss the proposed community micro programs, but also other development proposals at the macro level. At this Forum discussed the work program of each departments in elaboration of the mayor's vision, mission, and proposals from stakeholders which would then be measured and sorted to become a priority, the resulting output from this forum is the formulation of a policies regarding to the development.

\section{Acknowledgements}

Thank you to my supervisor Mrs. Erna Setijaningrium and Mr. Antun who contributed a lot in the making of this paper, ranging from data collection process until the completion of this paper. Thank you to our friends in the Public Policy Class of the Public Administration studies of Airlangga University that helped us during the data collection process as well as contribute a questions suggestions in the interview process.

Thanks also to Mr. Alfian as the facilitator of Bappeko who gives lectures and important information and facilitate us in the process of collecting the data in this paper. Also we say thank you to Mr. amir of Bappeko that contribute to facilitate us in obtaining data related to technical data electronically.

\section{References}

[1] Bappeko Surabaya. Pelaksanaan Musrenbang Kota Surabaya tahun 2014 Semakin Partisipatif dan Inovatif. Available: http://bappeko.surabaya.go.id. accessed on November, 18th 2016

[2] Estevez, Elsa, Pablo Fillottrani, and Tomasz Janowski. "From e-government to seamless government." Proceedings of the Conference on Collaborative Electronic Commerce Technology and Research, CollECTeR Iberoamerica 2007, Cordoba, Argentina. Vol. 1. 2007.

[3] Heeks, Richard. Understanding e-governance for development. Manchester: Institute for Development Policy and Management, 2001.

[4] HUMAS MENPAN-RB. Pemkot Surabaya akan dijadikan Model E-Govt Nasional. Available: http://www.menpan.go.id/ accessed on November, 18th 2016

[5] Palvia, Shailendra C. Jain, and Sushil S. Sharma. "E-government and e-governance: definitions/domain framework and status around the world." International Conference on E-governance. 2007.

[6] Seltzer, Ethan, and Dillon Mahmoudi. "Citizen participation, open innovation, and crowdsourcing: Challenges and opportunities for planning." CPL bibliography 28.1 (2013): 3-18. 